\title{
Changes in food intake during menstrual cycles and pregnancy of normal and diabetic rhesus monkeys
}

\author{
J. W. Kemnitz ${ }^{1}$, S. G. Eisele ${ }^{1}$, K. A. Lindsay ${ }^{1}$, M. J. Engle ${ }^{2}$, R. H. Perelman ${ }^{2}$ and P. M. Farrell ${ }^{2}$ \\ ${ }^{1}$ Wisconsin Regional Primate Research Center and ${ }^{2}$ Department of Pediatrics, University of Wisconsin-Madison, Madison, Wisconsin, USA
}

\begin{abstract}
Summary. Food intake of control and streptozotocin-diabetic rhesus monkeys was measured during menstrual cycles and pregnancy. Intake of control monkeys was lower at the time of ovulation than during other phases of the menstrual cycle. Intake of control monkeys was also low during most of pregnancy, but this was accompanied by normal fetal growth and net maternal weight gain. Diabetic monkeys ate more than controls in all conditions and their intake did not vary reliably according to reproductive status. It is suggested that (1) oestro-
\end{abstract}

gen normally inhibits food intake during menstrual cycles and pregnancy, (2) food energy is utilized more efficiently during pregnancy than during non-pregnant states, and (3) the influence of oestrogen on food intake is either attenuated by insulinopenia or is obscured by the hyperphagia typically exhibited by the diabetic monkeys.

Key words: Rhesus monkey, streptozotocin, food intake, oestrogen, menstrual cycles, pregnancy.
Caloric intake of females of several species varies according to reproductive condition. For example, food intake of most laboratory species is relatively low near the time of ovulation and it is elevated during pregnancy and lactation [17]. Primates have been less thoroughly studied in this regard, but periovulatory decreases in caloric intake have been reported for baboons [9] and macaques [3, 4, 15], as well as women [6]. Food intake is also generally presumed to increase during the primate pregnancy in order to accommodate fetoplacental development, but there is surprisingly little quantitative information on this topic. These fluctuations in food intake during reproductive cycles are thought to be mediated, to a large extent, by an inhibitory influence of oestrogen on eating behaviour $[4,16]$.

Food intake is elevated in cases of poorly controlled diabetes mellitus where insulin insufficiency impairs the utilization of blood-borne nutrients. The potential interactive effects of insulin and ovarian hormones on the modulation of caloric intake are of interest for two reasons. Firstly, predictable changes in hunger are of practical importance for counselling insulin-dependent women; secondly, the documentation of these effects would provide insight into the mechanism of action of these hormones on behaviour. In this report we describe food intake of normal and diabetic rhesus monkeys in relation to their reproductive condition.

\section{Materials and methods}

Fourteen adult female Macaca mulatta were included in these observations as part of a project designed to explore the mechanisms for abnormal lung maturation in fetuses of diabetic mothers [11, 13]. Seven of them were treated with the pancreatic B cell toxin streptozotocin (STZ; $47.5 \mathrm{mg} / \mathrm{kg}$ ). All STZ-treated animals exhibited marked glucose intolerance during glucose tolerance tests conducted 4-6 weeks after STZ treatment [11]. Six of these animals were maintained for approximately 1 year before insulin therapy was initiated. At that time insulin was given to arrest the progressive deterioration of their physical condition. The remaining monkey required daily insulin within 2 weeks of STZ treatment. Insulin therapy was designed to maintain fasting plasma glucose values in the range of $8.5-19.5 \mathrm{mmol} / 1$ by a single daily injection of 5-20 units of NPH insulin or NPH plus $2.5-5$ units of soluble insulin [11]. Seven control animals comparable in age and weight to STZ-treated animals were studied concurrently (Table 1).

All animals were individually housed in metabolic cages $(76 \mathrm{~cm} \times 71 \mathrm{~cm} \times 79 \mathrm{~cm}$ high) in a room which was artificially lighted from 06.00 to $18.00 \mathrm{~h}$ and maintained at approximately $21^{\circ} \mathrm{C}$. Tap water was available ad libitum and high protein Purina monkey chow $(25 \%$ protein, $4.3 \mathrm{kcal} / \mathrm{g}$ ) was also freely available except during occasional overnight deprivations for experimental purposes. Daily food intake was measured by calculating the difference between the number of biscuits given to each animal in the morning and the number remaining in the cage and drop pan the following morning. Average biscuit weights were determined by weighing a sample of 50 biscuits from each bag of chow. One or two pieces of fruit were also fed one to two times daily; this was always quickly and completely eaten. The animals were weighed at least weekly during the period of observation. 
Table 1. Characteristics of diabetic and control monkeys

\begin{tabular}{lllll}
\hline Animal & $\begin{array}{l}\text { Age }^{\mathrm{a}} \\
\text { (years) }\end{array}$ & $\begin{array}{l}\text { Weight } \\
(\mathrm{kg})\end{array}$ & \multicolumn{2}{l}{$\begin{array}{l}\text { Number of menstrual } \\
\text { cycles }\end{array}$} \\
\cline { 3 - 5 } & & & $\begin{array}{l}\text { Without } \\
\text { insulin } \\
\text { therapy }\end{array}$ & $\begin{array}{l}\text { With } \\
\text { insulin } \\
\text { therapy }\end{array}$ \\
\hline STZ-treated & & & & \\
U14 & 6 & 4.93 & 3 & 3 \\
U06 & 6 & 4.23 & 3 & 5 \\
E58 & 14 & 6.44 & 6 & 7 \\
N68 & 8 & 6.33 & 1 & 0 \\
1681 & 10 & 4.39 & 1 & 1 \\
1682 & 12 & 5.56 & 1 & 0 \\
R53 & 7 & 6.34 & 0 & 11 \\
Control & & & & \\
U78 & 6 & 5.50 & 2 & - \\
F48 & 13 & 8.88 & 8 & - \\
I58 & 11 & 7.02 & 9 & - \\
1767 & 6 & 3.82 & 4 & - \\
F51 & 13 & 6.50 & 1 & - \\
H47 & 14 & 6.25 & 2 & - \\
1686 & 13 & 6.70 & 4 & \\
\hline
\end{tabular}

a At STZ treatment or beginning of observation period

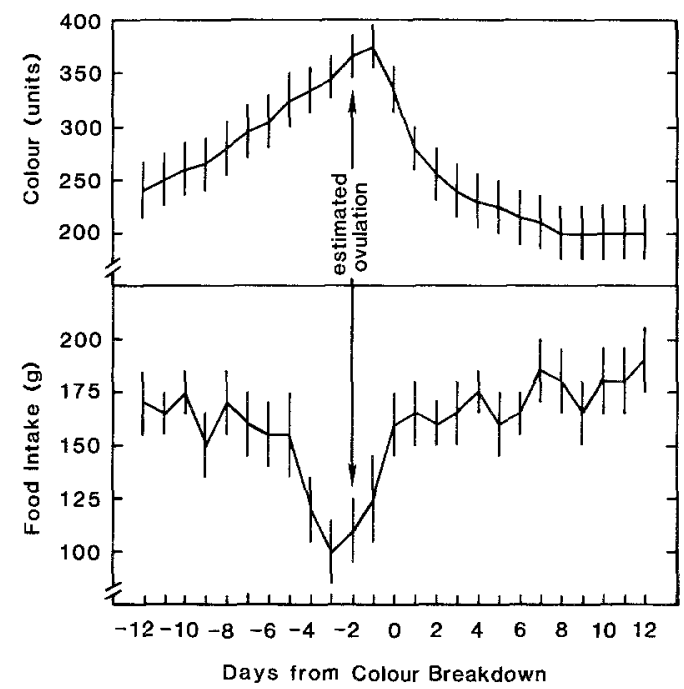

Fig. 1. Ratings of intensity of colouration of the sexual skin (upper panel) and food intake (lower panel) during the middle 25 days of 30 normal menstrual cycles of seven monkeys. Results expressed as mean \pm SEM

Table 2. Food intake during phases of menstrual cycle

\begin{tabular}{llccc}
\hline Animals & \multicolumn{2}{l}{ Food intake $(\mathrm{g})$} & & \\
\cline { 2 - 5 } & Early follicular & Pre-ovulatory & Mid-luteal & Late luteal \\
\hline Control $(n=7)$ & $173 \pm 20^{\mathrm{a}}$ & $97 \pm 16^{\text {a b }}$ & $179 \pm 15^{\text {a }}$ & $165 \pm 12^{\text {a }}$ \\
Diabetic, without insulin therapy $(n=6)$ & $280 \pm 25$ & $259 \pm 24$ & $287 \pm 22$ & $269 \pm 25$ \\
Diabetic, with insulin therapy $(n=5)$ & $266 \pm 22$ & $251 \pm 34$ & $266 \pm 35$ & $243 \pm 19$ \\
\hline
\end{tabular}

Results expressed as mean $\pm \mathrm{SEM}$

a $<$ both groups of diabetic monkeys, $p<0.001 ; \quad b<$ during other phases, $p<0.001$

Daily ratings of intensity of colouration of the sex skin were made and occurrence of menstruation was noted. A pattern of increasing values for colour ratings for $2-3$ weeks followed by a precipitous decline (colour breakdown) and then menstruation 12-18 days later is considered to indicate an ovulatory cycle [5]. Ovulation usually occurs 2 days before colour breakdown. Food intake data from apparently normal menstrual cycles were aligned relative to the day of colour breakdown for descriptive purposes. For statistical analysis, four periods of these cycles were defined: the early follicular phase ( 5 days beginning with the first day of menstruation), pre-ovulatory phase (days 2-4 before colour breakdown), the midluteal phase (5 days midway between the day of presumed ovulation and the first day of subsequent menstruation), and the late luteal phase ( 4 days immediately preceding menstruation).

Matings were performed during some cycles at the time of anticipated ovulation. When pregnancies ensued food intake data were similarly aligned relative to the estimated day of conception. Pregnancies were terminated by Caesarean section delivery on days 142-145 of gestation for the purposes of a related study [13].

Data were statistically evaluated by analysis of variance with Newman-Keuls tests, Student's t-test, and Pearson's Product Moment Correlation Coefficient.

\section{Results}

Average food intake of seven control monkeys during 30 menstrual cycles is illustrated in Figure 1. Intake of this group averaged between $150-200 \mathrm{~g}$ / day except at midcycle when there was a marked decrease. Intake of these monkeys was significantly lower during the preovulatory phase than during the early follicular, midluteal and late luteal phases (Table 2). This pattern of lowest intake during the pre-ovulatory phase was consistently evident for six of the seven animals and for $81 \%$ of all cycles studied. Neither average food intake nor magnitude of suppression of intake at ovulation was related to body weight.

Three monkeys in the control group became pregnant during the period of observation. Average scores for sex skin colouration, food intake, and body weight for these pregnancies are illustrated in Figure 2. Colour scores varied during the cycle of conception and during early pregnancy reflecting changes in oestrogen secretion by the ovary and placenta, and then remained high during the second and third trimesters when oestrogen levels are also elevated [2]. Colour intensity decreased when the fetus and placenta were delivered. Food intake varied inversely with colour ratings before, during, and after pregnancy, and it was not higher during pregnancy than in the non-pregnant state. For example, intake of these three monkeys during the pre-ovulatory 
Table 3. Characteristics of pregnant monkeys

\begin{tabular}{|c|c|c|c|c|c|c|}
\hline Animal & Insulin therapy & $\begin{array}{l}\text { Weight at } \\
\text { conception } \\
(\mathrm{kg})\end{array}$ & $\begin{array}{l}\text { Weight gain } \\
\text { during pregnancy } \\
\text { (kg) }\end{array}$ & $\begin{array}{l}\text { Fasting blood } \\
\text { glucose }^{\mathrm{a}} \\
(\mathrm{mmol} / \mathrm{l})\end{array}$ & $\begin{array}{l}\mathrm{Kg}^{\mathrm{b}} \\
(\% / \mathrm{min})\end{array}$ & $\begin{array}{l}\text { Fetal } \\
\text { weight } \\
\text { (g) }\end{array}$ \\
\hline H47 & - & 6.83 & 1.52 & 3.7 & 3.94 & 448 \\
\hline F51 & - & 6.45 & 0.35 & 5.9 & 4.85 & 374 \\
\hline 1686 & - & 6.46 & 1.75 & 2.2 & 5.22 & 420 \\
\hline $1681-2$ & $\begin{array}{l}15 \mathrm{U} \text { NPH+ } \\
5 \mathrm{U} \text { soluble }\end{array}$ & 4.90 & 1.45 & 13.5 & 0.87 & 341 \\
\hline E58 & $\begin{array}{c}10-20 \mathrm{U} \mathrm{NPH}+ \\
2.5-5 \mathrm{U} \text { soluble }\end{array}$ & 9.30 & 0.24 & 14.4 & 1.41 & 529 \\
\hline
\end{tabular}

${ }^{a}$ On day 125 of pregnancy; ${ }^{b} \mathrm{Kg}=$ glucose disappearance rate during an intravenous glucose tolerance test on day 125 of pregnancy [11];

$c$ At delivery, day 142-145 of pregnancy

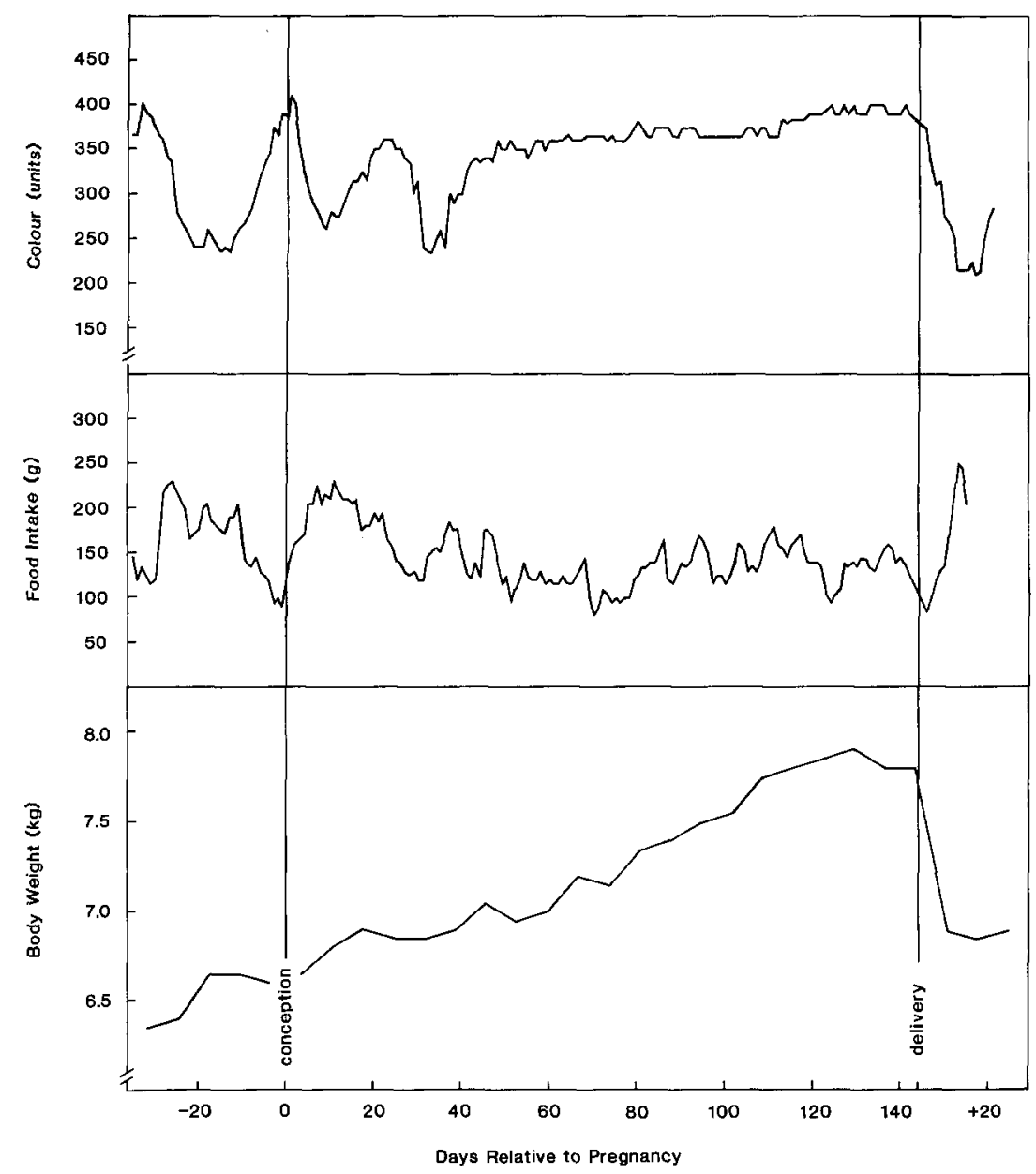

Fig. 2. Mean daily ratings of sex skin colouration (upper panel), daily measures of food intake (centre panel), and weekly body weights (lower panel) during three control pregnancies phase of menstrual cycles averaged $72 \%$ of midluteal values. Similarly, from week 8 of pregnancy until delivery food intake averaged $76 \%$ of the mid-luteal mean $(132 \pm 10$ versus $181 \pm 19 \mathrm{~g} /$ day). In spite of this $24 \%$ average reduction in caloric intake during most of pregnancy, maternal body weight increased by $1.2 \mathrm{~kg}$ from conception until delivery, and following delivery it re- mained $0.3 \mathrm{~kg}$ higher than the value at conception. Fetal development in these pregnancies was normal for gestational age [11], and fetal body weights at delivery averaged $414 \mathrm{~g}$ (Table 3). Food intake was not related to maternal weight in these pregnancies, but the mother who ate the least gained the least weight and had the smallest fetus. 
Diabetic monkeys ate more chow than control monkeys and average values of intake were not detectably related to stages of the menstrual cycle (Table 2). Intake of diabetic monkeys was typically at least $50 \%$ greater than that of controls and it was not affected by the insulin dosages employed here. (It should be noted, however, that the insulin therapy was designed to moderate but not eliminate hyperglycaemia.)

Three pregnancies of diabetic monkeys have been studied under these conditions. One monkey was observed during two pregnancies, one with and one without insulin therapy, while the third pregnancy was of another insulin-treated monkey (Table 3). Intake during these pregnancies was more variable than observed during pregnancies of normal monkeys, and no reliable relationship between food intake and colour ratings was detected. Maternal weight gain during pregnancy was $0.8 \mathrm{~kg}$ and after delivery average maternal weight was $0.3 \mathrm{~kg}$ less than at conception. Weights of these offspring of diabetic mothers averaged $500 \mathrm{~g}$ (Table 3 ).

\section{Discussion}

The present observation of decreased food intake during the pre-ovulatory phase of the menstrual cycle is consistent with several previous reports. Gilbert and Gillman [9] monitored intake of three baboons during three menstrual cycles each and reported decreased intake of a mixed diet during the follicular phase of the cycle. Czaja [3, 4] and Rosenblatt et al. [15] studied thesus monkeys fed a standard commercial diet and found a decrease in intake at midcycle. Dalvit [6], utilizing interview data from a sample of eight women who were not aware of the purpose of the study, found that intake was lower during the follicular phase than during the luteal phase. The present report differs from the previous studies in that the subjects had a standardized [6,9], high-protein diet $[3,4,15]$, which was continuously available $[3,4,9,15]$. Thus, the present results confirm and extend the observation of systematic changes in food intake during the primate ovarian cycle.

Spontaneous caloric intake during pregnancy has not been adequately defined for any primate species, but the prevailing assumption is that it increases. Consistent with this, Czaja [3] found that the proportion of pregnant rhesus monkeys that did not eat all of their allotted daily food decreased from $50 \%$ during week 6 of pregnancy to less than $10 \%$ by week 14 . Similarly, Riopelle et al. [14] reported a $20 \%$ increase in caloric intake after week 6 of pregnancy for animals eating a semi-purified diet containing $13 \%$ protein. Kohrs et al. [12], on the other hand, indicated that rhesus monkeys meal-fed an $11 \%$ protein liquid diet displayed a $10 \%$ reduction in intake after day 80 of pregnancy. It is difficult to evaluate these apparently contradictory results because of methodological differences among the studies. However, the present observation of relatively low intake af- ter the second month of pregnancy for monkeys allowed to eat ad libitum provides further support for the existence of an inhibitory influence on eating behaviour during the primate pregnancy.

It is difficult to assess accurately the caloric intake of women, particularly over long periods of time such as encompassed by pregnancy. Furthermore, the pregnant woman is likely to be influenced by nutritional advice which may or may not be supported by sound evidence. However, the results of two extensive studies of intake of pregnant women are consistent with the observations of rhesus monkeys reported here $[1,7]$. In both clinical studies caloric intake was found not to increase during pregnancy and it actually tended to decrease after the second trimester. It was also noted that obesity was more likely to occur during pregnancy than was nutritional deficiency [7]. Continued development of a non-human primate model would enhance our understanding of the energy requirements of the human pregnancy.

Oestrogen has been shown to exert a suppressive effect on food intake of primates. Oestrogen injections [4] or implants [10] given to ovariectomized monkeys lead to a dose-related reduction in food intake. Also, oestrogen levels are elevated during the pre-ovulatory phase of the menstrual cycle when intake is lowest. Reduced intake during the later portion of pregnancy is consistent with the notion of an oestrogen-mediated inhibition of eating. It is more difficult, however, to reconcile the substantial weight gain observed during pregnancy with this lower energy intake. There must be a corresponding decrease in energy expenditure to account for this imbalance. Further studies of physical activity and metabolic activity of pregnant monkeys would be very helpful in this regard.

Intake of diabetic monkeys was greater than that of controls. Although food intake did not vary reliably according to reproductive condition, pre-ovulatory decreases in food intake were evident during some menstrual cycles of diabetic animals. In one case involving an insulin-dependent monkey, such a pre-ovulatory reduction was probably responsible for an episode of hypoglycaemic shock. The absence of a statistically significant relationship between phase of the cycle and food intake may be attributable to the consistently elevated and generally more variable intake of the diabetic animals. However, a study of ovariectomized diabetic rats suggested a decreased sensitivity to the anorexic effects of exogenous oestrogen [8]. Continued studies of energy balance of normal and diabetic animals during reproductive cycles will be necessary to resolve these issues completely.

\footnotetext{
Acknowledgements. We are grateful to the Animal Care Staff for conscientious help with the animals and to M.Schatz and J. Kinney for secretarial assistance. Insulin was supplied by M.L. Sullivan, R. Ph., of Eli Lilly. This work was supported by HD11429, RR00167, and HL27358 from the National Institutes of Health. This is publication number 23-002 of the Wisconsin Regional Primate Research Center.
} 


\section{References}

1. Beal VA (1971) Nutritional studies during pregnancy. J Am Dietet Assoc 58: 312-320

2. Bielert C, Czaja JA, Eisele SG, Scheffler G, Robinson JA, Goy RW (1976) Mating in the rhesus monkey (Macaca mulatta) after conception and its relationship to oestradiol and progesterone levels throughout pregnancy. Reprod Fertil 46: 179-187

3. Czaja JA (1975) Food rejection by female rhesus monkeys during the menstrual cycle and early pregnancy. Physiol Behav 14: 579-587

4. Czaja JA (1978) Ovarian influences on primate food intake: Assessment of progesterone actions. Physiol Behav 21:923-928

5. Czaja JA, Robinson JA, Eisele SG, Scheffler G, Goy RW (1977) Relationship between sexual skin colour of female rhesus monkeys and midcycle plasma levels of oestradiol and progesterone. $J$ Reprod Fertil 49: 147-150

6. Dalvit SP (1981) The effect of the menstrual cycle on patterns of food intake. Am J Clin Nutr 34: 1811-1815

7. Darby WJ, McGanity WJ, Martin MP, Bridgeforth E, Densen PM, Kaser MM, Ogle PJ, Newbill JA, Stockell A, Ferguson ME, Touster O, McClellan GS, Williams C, Cannon RO (1953) The Vanderbilt Cooperative Study of maternal and infant nutrition. IV. Dietary, laboratory, and physical findings in 2,129 delivered pregnancies. J Nutr 51: 565-597

8. Dudley SD, Gentry T, Silverman BS, Wade GN (1979) Estradiol and insulin: independent effects on eating and body weight in rats. Physiol Behav 22: 63-67

9. Gilbert C, Gillman J (1956) The changing pattern of food intake and appetite during the menstrual cycle of the baboon (Papio ursinus) with a consideration of some of the controlling endocrine factors. S Afr Med Sci 21: 75-88

10. Kemnitz JW, Lindsay KA, Gibber JR (1982) Ovarian influences on food intake, body weight, and sucrose consumption of rhesus monkeys. Int J Primatol 3: 303
11. Kemnitz JW, Perelman RH, Engle MJ, Farrell PM (1983) An experimental model for studies of fetal maldevelopment in the diabetic pregnancy. Pediatrics (in press)

12. Kohrs MB, Harper AE, Kerr GR (1976) Effects of a low-protein diet during pregnancy of the rhesus monkey. I. Reproductive efficiency. Am J Clin Nutr 29: 136-145

13. Perelman RH, Engle M, Kemnitz J, Kotas R, Farrell P (1982) Concurrent biochemical and physiological analysis of fetal lung development in the rhesus monkey (Macaca mulatta). J Appl Physiol 53: $230-235$

14. Riopelle AJ, Hill CW, Li S-C, Wolf RH, Seibold HR, Smith JL (1975) Protein deficiency in primates. IV. Pregnant rhesus monkey. Am J Clin Nutr 28: 20-28

15. Rosenblatt H, Dyrenfurth I, Ferin M, Vande Wiele RL (1980) Food intake and the menstrual cycle of rhesus monkeys. Physiol Behav 24: 447-449

16. Wade GN (1975) Some effects of ovarian hormones on food intake and body weight in female rats. J Comp Physiol Psychol 88: 183-193

17. Wade GN (1976) Sex hormones, regulatory behaviours and body weight. In: Rosenblatt JS, Hinde RA, Shaw E, Bear GC (eds) Advances in the study of behavior, Vol.6. Academic Press, New York, pp 201-279

Received: 28 February 1983

and in revised form: 21 July 1983

Dr. Joseph W. Kemnitz

Wisconsin Regional Primate Research Center

1223 Capitol Court,

Madison, WI 53715-1299

USA 